\title{
Use of Methylphenidate Analogues as Cognitive Enhancers: The Prelude to Cosmetic Neurology and an Ethical Issue
}

\author{
Simona Zaami ${ }^{1}$, Adriano Tagliabracci ${ }^{2}$, Paolo Berretta ${ }^{3}$, Francesco Paolo Busardò ${ }^{2 *}$ \\ and Enrico Marinelli ${ }^{1}$ \\ ${ }^{1}$ Department of Anatomical, Histological, Forensic, and Orthopedic Sciences, Sapienza University, Rome, Italy, ${ }^{2}$ Section of \\ Legal Medicine, Department of Excellence-Biomedical Sciences and Public Health, Ancona, Italy, ${ }^{3}$ National Centre on \\ Addiction and Doping, Istituto Superiore di Sanità, Rome, Italy
}

Keywords: cognitive enhancers, mental health, alterations, medical ethics, cosmetic neurology

OPEN ACCESS

Edited by: Magi Farre,

Hospital Germans Trias i Pujol, Spain

Reviewed by:

Fabrizio Schifano, University of Hertfordshire, United Kingdom

*Correspondence:

Francesco Paolo Busardò fra.busardo@libero.it

Specialty section:

This article was submitted to

Addictive Disorders,

a section of the journal

Frontiers in Psychiatry

Received: 11 October 2019 Accepted: 20 December 2019

Published: 23 January 2020

Citation:

Zaami S, Tagliabracci A, Berretta $P$, Busardò FP and Marinelli E (2020) Use of Methylphenidate Analogues as

Cognitive Enhancers: The

Prelude to Cosmetic

Neurology and an Ethical Issue.

Front. Psychiatry 10:1006.

doi: 10.3389/fpsyt.2019.01006

\section{INTRODUCTION}

Drugs involved in the treatment of Alzheimer's disease and other cognitive deficits such as attention deficit hyperactivity disorder (ADHD), strokes, schizophrenia, and aging are medically defined as cognitive enhancers (1). Amphetamines were the first drugs used to stimulate memory consolidation and improve concentration, and were followed by non-amphetaminic central nervous system (CNS) stimulants modafinil and armodafinil, which are largely prescribed for the treatment of narcolepsy and ADHD, although their mechanism of action is not entirely understood. Atomoxetine, a selective nor-adrenaline reuptake inhibitor, has been used in children with medication-resistant ADHD or undergoing side effects related to other drugs, while donepezil, a second-generation acetylcholinesterase inhibitor, has been employed for the treatment of mild-tomoderately-severe symptoms of Alzheimer-related dementia (2).

Nevertheless, methylphenidate is undoubtedly the most prescribed cognitive enhancer. It is also the most misused. Indeed, the non-medical use of methylphenidate and cognitive enhancers in an attempt to improve memory, increase mental concentration, control anxiety, and stimulate motivation and creativity is a rising worldwide phenomenon $(2,3)$. Due to methylphenidate being a prescription drug with medical restrictions in several countries, many illegal analogues have emerged on the internet and darknet drug markets during the last few years (3).

The misuse of cognitive enhancers in adults and young healthy individuals with the aim of increasing neurological functions is part of a phenomenon defined as "cosmetic neurology" (2). In addition, psychedelic microdosing using small doses of psychedelic substances, such as LSD and psilocybin is becoming more common (4). However, this cognitive enhancement comes with mental and ethical costs.

\section{Risks for Physical and Mental Health of Cognitive Enhancers}

The physical and mental health risks associated with the use of methylphenidate analogues such as ethylphenidate, 3,4-dichloromethylphenidate, 3,4-dichloroethylphenidate, 4fluoromethylphenidate, 4-fluoroethylphenidate, methylnaphthidate, ethylnaphthidate, isopropylphenidate, propylphenidate, 4-methylmethylphenidate, and N-benzylethylphenidate 
were recently reviewed and several severe intoxications and fatalities were reported (5). Moreover, the neurological and psychiatric consequences due to the misuse of methylphenidate analogues have been carefully evaluated. Psychiatric manifestations such as impulsive behavior, verbal, visual and memory impairment, gambling, compulsive shopping, and hypersexuality have been demonstrated, especially in younger users, due to excessive dopaminergic stimulation $(2,6)$. Furthermore, "psychostimulants" also alter the glutamatergic system, which can result in the impairment of behavioral flexibility and lead to the development and/or potentiation of addictive behaviors. Methylphenidate was proven to lower drug abuse liability in patients with ADHD. Still, it may also lead to similar behavioral rigidity and increase the risk for addictive or obsessive-compulsive behaviors, since the drug impacts glutamatergic signalling $(3,5)$.

Ethical issues raised by cognitive enhancement have been debated for over a decade (7): foremost experts have identified multiple ethical concerns including risks to mental and health safety. In 2015, the US Presidential Commission for the Study of Bioethical Issues (Bioethics Commission) released a report on the issue of cognitive enhancement, reporting findings, and establishing recommendations for the scientific community (8). A major issue is the current medical acceptance, or even endorsement, of interventions intended to restore or sustain "normality." Both explicitly and implicitly, such a stance arguably adheres to the idea of a set of essential sociocultural requirements to function "normally", considering abnormal or antisocial any deviation from established standards (3).

Remarks from the Australian Alcohol and Drug Foundation (9) have cast doubts on the actual cognitive benefits of most enhancers, indicating that scientific studies showed only little to no benefits for cognitive enhancement in healthy individuals, while the associated side effects do pose health risks (10). Furthermore, granted that the use of cognitive enhancers may somehow help in masking fatigue, boredom or procrastination, there is no evidence to suggest that they can actually make people smarter. Moreover, their effects are apparently temporary, lasting until their metabolization and elimination (11). Some of these drugs can cause dependence and have a wide range of side effects. They can be particularly harmful to young people as brains are not fully developed until the age 25 .

\section{Medical Ethics}

In 2014, the Italian Code of Medical Ethics included for the first time a new article defining human enhancement and related

\section{REFERENCES}

1. Newman LA, McGaughy J. Adolescent rats show cognitive rigidity in a test of attentional set shifting. Dev Psychobiol (2011) 53:391-401. doi: 10.1002/ dev.20537

2. Frati P, Kyriakou C, Del Rio A, Marinelli E, Vergallo GM, Zaami S, et al. Smart drugs and synthetic androgens for cognitive and physical enhancement: revolving doors of cosmetic neurology. Curr Neuropharmacol (2015) 13:5-11. doi: 10.2174/1570159X13666141210221750 medical practices (12). The article was meant to reflect the relationship between this new field of medical practice and professional ethics. The article allowed for medical treatments going beyond conventional therapeutic goals, as long as several ethical and clinical criteria were met. Nonetheless, the problematic application of these criteria to human enhancement generated issues warranting an in-depth reflection.

\section{DISCUSSION}

The 2014 article of the Italian Code of Medical Ethics was replaced in 2017 by two new articles (76 and 76 -BIS), which are currently enforced (13). The new articles focus on medical enhancement and cosmetic medicine, stating that medical doctors being asked to provide or prescribe cognitive enhancers must always act in adherence to the highest standards of respect and protection for human dignity, human identity and integrity, and the inherent genetic traits in accordance with the principles of proportionality and precaution.

Nevertheless, it was shown that off-label use of cognitive enhancers can be efficacious in the treatment of postoperative cognitive dysfunction after major surgery in elderly patients, significantly decreasing the incidence of neurocognitive deficits (14). Other neuroscientists reported benefits for jobs requiring adaptive learning or attention shifting under pressure and recommend further research on the safety and efficacy of cognitive enhancers (15).

In the meantime, more reliable means to enhance cognitive functions should be promoted and prioritized: education, constant intellectual exercise and learning, a rewarding social life, interaction, a stimulating and healthy lifestyle. Such an approach is certainly more demanding and time-consuming than taking a supposedly "enhancing" drug, but it is much better for the individual in terms of personal identity development, creation of satisfactory interrelationships, selfesteem, and self-fulfilment.

\section{AUTHOR CONTRIBUTIONS}

SZ and FB provided initial idea and construct of the opinion. $\mathrm{PB}$, AT, and EM co-authored and edited the manuscript.

3. Busardò FP, Kyriakou C, Cipolloni L, Zaami S, Frati P. From clinica application to cognitive enhancement: the example of methylphenidate. Curr Neuropharmacol (2016) 14:17-27. doi: 10.2174/1570159X13666150407225902

4. Anderson T, Petranker R, Christopher A, Rosenbaum D, Weissman C, DinhWilliams LA, et al. Psychedelic microdosing benefits and challenges: an empirical codebook. Harm Reduct J (2019) 16:43. doi: 10.1186/s12954-0190308-4

5. Carlier J, Giorgetti R, Varì MR, Pirani F, Ricci G, Busardò FP. Use of cognitive enhancers: methylphenidate and analogs. Eur Rev Med Pharmacol Sci (2019) 23:3-15. doi: 10.26355/eurrev_201901_16741 
6. Freedman D, Zaami S. Neuroscience and mental state issues in forensic assessment. Int J Law Psychiatry (2019) 65:101437. doi: 10.1016/j.ijlp.2019.03.006

7. Bostrom N, Sandberg A. Cognitive enhancement: methods, ethics, regulatory challenges. Sci Eng Ethics (2009) 15:311-41. doi: 10.1007/s11948-009-9142-5

8. Presidential Commission for the Study of Bioethical Issues. Gray Matters: Topics at the Intersection of Neuroscience, Ethics, and Society. (2015). https://bioethicsarchive.georgetown.edu/pcsbi/node/4704.html (Accessed October 2019).

9. Alcohol and Drug Foundation. Nootropics. https://adf.org.au/drug-facts/ cognitive-enhancers/ (Accessed October 2019).

10. Hall WD, Lucke JC. The enhancement use of neuropharmaceuticals: more scepticism and caution needed. Addiction (2010) 105:2041-3. doi: 10.1111/ j.1360-0443.2010.03211.x

11. De Jongh R, Bolt I, Schermer M, Olivier B. Botox for the brain: enhancement of cognition, mood and pro-social behavior and blunting of unwanted memories. Neurosci Biobehav Rev (2008) 32:760-76. doi: 10.1016/ j.neubiorev.2007.12.001

12. Montanari Vergallo G, Busardò FP, Zaami S, Marinelli E. The static evolution of the new Italian code of medical ethics. Eur Rev Med Pharmacol Sci (2016) 20:575-80.

13. Federazione Nazionale degli Ordini dei Medici Chirurghi e degli Odontoiatri. Codice di Deontologia Medica. (2014). Article 76 was modified on 15th
December, 2017. https://portale.fnomceo.it/wp-content/uploads/2018/03/ CODICE-DEONTOLOGIA-MEDICA-2014.pdf (Accessed October 2019).

14. Setacci C, Sirignano A, Ricci G, Spagnolo AG, Pugliese F, Speziale F. A new ethical and medico-legal issue: vascular surgery and the postoperative cognitive dysfunction. J Cardiovasc Surg (2015) 56:607-15. https://portale. fnomceo.it/wp-content/uploads/2018/03/CODICE-DEONTOLOGIAMEDICA-2014.pdf. Accessed October 2019

15. Savulich G, Piercy T, Brühl AB, Fox C, Suckling J, Rowe JB, et al. Focusing the neuroscience and societal implications of cognitive enhancers. Clin Pharmacol Ther (2017) 101:170-2. doi: 10.1002/cpt.457

Conflict of Interest: The authors declare that the research was conducted in the absence of any commercial or financial relationships that could be construed as a potential conflict of interest.

Copyright (c) 2020 Zaami, Tagliabracci, Berretta, Busardo and Marinelli. This is an open-access article distributed under the terms of the Creative Commons Attribution License (CC BY). The use, distribution or reproduction in other forums is permitted, provided the original author(s) and the copyright owner(s) are credited and that the original publication in this journal is cited, in accordance with accepted academic practice. No use, distribution or reproduction is permitted which does not comply with these terms. 